\title{
Knowledge generation and utilization in wiki supported teamwork - An experiment
}

\section{Kasa, Richard ${ }^{\text {; }}$ Heidrich, Balazs ${ }^{\mathrm{a}}$}

${ }^{\mathrm{a}}$ Faculty of Finance and Accountancy, Budapest Business School, Hungary

\begin{abstract}
With the rapid advance of communication technologies and the free-flow of information, the concept of collaboration extends beyond physical locations and time zones in the form of virtual teams that are globally connected. This study considers how modern Web 2.0 based collaborative technologies (wikis) relate knowledge creation and utilization in student groups and aims to find out if these collaborative technologies are better suited to tasks requiring extensive asynchronous collaboration in an educational setting. To perform controlled experiments a sample of student teams that have worked in technologically and demographically diverse groups was selected, from which we had 49 experimental and 48 control teams with 193 and 192 participants respectively. We found that wiki technologies do not suit all kinds of tasks and do not always increase knowledge creation, knowledge maintenance, problem solving and thus knowledge utilization in team collaboration.
\end{abstract}

Keywords: wiki; web-2; knowledge creation; teamwork. 


\section{Introduction}

The current pace of technological development is forcing higher education teachers and trainers to keep up with the latest IT innovations in order to transform the static learning process into a dynamic cognitive process. Collaborative learning enables users to capitalize on each other's resources, skills and ideas in an environment where participants are engaged in a common task and goal with every individual dependent on and accountable to the others. The field of this collaboration can be effectively supported with innovative technology.

It is presently unclear how these technologies influence learning and problem-solving processes as studies often investigate the problem unilaterally with a focus on certain kinds of tasks and technologies and usually inadequately from a methodological and statistical point of view. This research is intended to overcome these deficiencies with an extended experiment based on an original concept of (Shu \& Chuang, 2011, 2012) and rigorous statistical methodology. The experiment separates tasks and technologies and measures their respective fit and the evolution of productivity and decision quality during the solving of case studies under controlled conditions. The paper seeks to illuminate the relationship between different types of tasks and technologies from several aspects.

\section{Recent Trends in Web-Based Team Collaboration}

Recently, internet is returning to its origins as a read/write tool and entering a new, social phase as a participatory tool. This second wave has led Darcy DiNucci to create the term Web 2.0 (or web2) for those Web sites that allow users to interact and collaborate with each other in a social media dialogue as creators of user-generated content in a virtual community.

Web 2.0 technologies enable remarkable interactivity and create many new collaboration models such as Wikipedia or InnoCentive. What encourages us is not only its popularity but its idiosyncrasy; simple and parallel editing, version control, and real-time updates (Trkman \& Trkman, 2009), in contrast to the 'bottleneck effect' referred to by Bean \& Hott (2005), where updates are delayed through a centrally managed entry. Created by Ward Cunningham in 1995, wikis are web-based hypertext applications intended for collaborative writing. In addition to writing and viewing their own pages in real time, people who use a wiki can see pages others have published and hyper-textually link to them without having to wait for an editor to assemble the various components developed individually on multiple PCs. During the writing process, content can be displayed immediately to other team members, who can immediately add their own contributions and see others' revisions without having to wait for an editor to assemble the various elements from people working on other PCs (Lin, Chuang, \& Shu, 2012). McAfee argued that "the technologists of Enterprise 2.0 (e.g. wikis) are trying hard not to impose on users any preconceived notions 
about how work should proceed or how output should be categorized or structured. Instead, they are building tools that let these aspects of knowledge work emerge" (McAfee, 2006). Wikis have evolved as a tool capable of matching these various characteristics (Lin et al., 2012). Instead of serving as a control centre, a wiki serves as a collaboration and creation platform and a central repository. This makes asynchronous cooperation across time zones possible. Beyond the alleviation of physical constraints, the potential for greater collaboration is further augmented by the usage of wikis in the following three ways: Wiki provides an equal opportunity for all opinions to be heard. As Bean \& Hott (2005) commented, rather than the back-and-forth exchanges of e-mail attachments or discussion boards, wiki allows direct exchanges of opinions centrally and stored permanently, enhancing the efficiency of the organisation through the increased teamwork efficiency as recent studies show (Hadjerrouit, 2014; Li, 2013; Wang, Zou, Wang, \& Xing, 2013). However, these studies omit many aspects of wiki collaboration and are lacking methodologically.

Secondly, unlike blogs or micro-blogs available today, wiki usage allows two-way communication, which makes it a dynamic process closely resembling real life communication as referred to by Zhang, Fang, Wei, \& He (2013). Mattison (2003) pointed out that when compared to blogs, most wikis provide forums where authors can discuss and resolve conflicting opinions through seeing others' postings and offer their own thoughts.

Lastly, the entire methodology is built on trust, which means all entries are assumed to be genuine and correct and filters are established only when necessary. The assumed trust and the way a wiki encourages continuous enhancement of data, in turn harnesses the power of diverse individuals to create collaborative works globally (Shu \& Chuang, 2012).

\section{Research methodology and model framework}

During the entire research process the methodology presented in Lin et al. (2012), Shu \& Lee (2003), and Shu \& Chuang (2012) were followed. This methodology is based on the separation of collaborative tasks into intellectual type and preference type tasks on the one hand, and the separation of collaborative technologies to traditional (face-to-face meetings) and wiki Web 2.0 based technologies on the other. The aim is to measure the fit of the two dimensions (tasks and technologies) and team performance (see figure 1).Zigurs \& Buckland (1998) have shown that groups adopting a group support system are more motivated to express their ideas than groups that do not. Additionally, systems that support parallel editing and allow multiple participants to instantly share and express their opinions, ideas, and information could be far more efficient than conventional systems in which editing and expression are sequential (Berndt, 1992). In this paper we put forward hypotheses concerning the effect of systems (wiki technologies) on knowledge utilization in teamwork. 
Our research model is based on a causal path model as it is in figure 1.

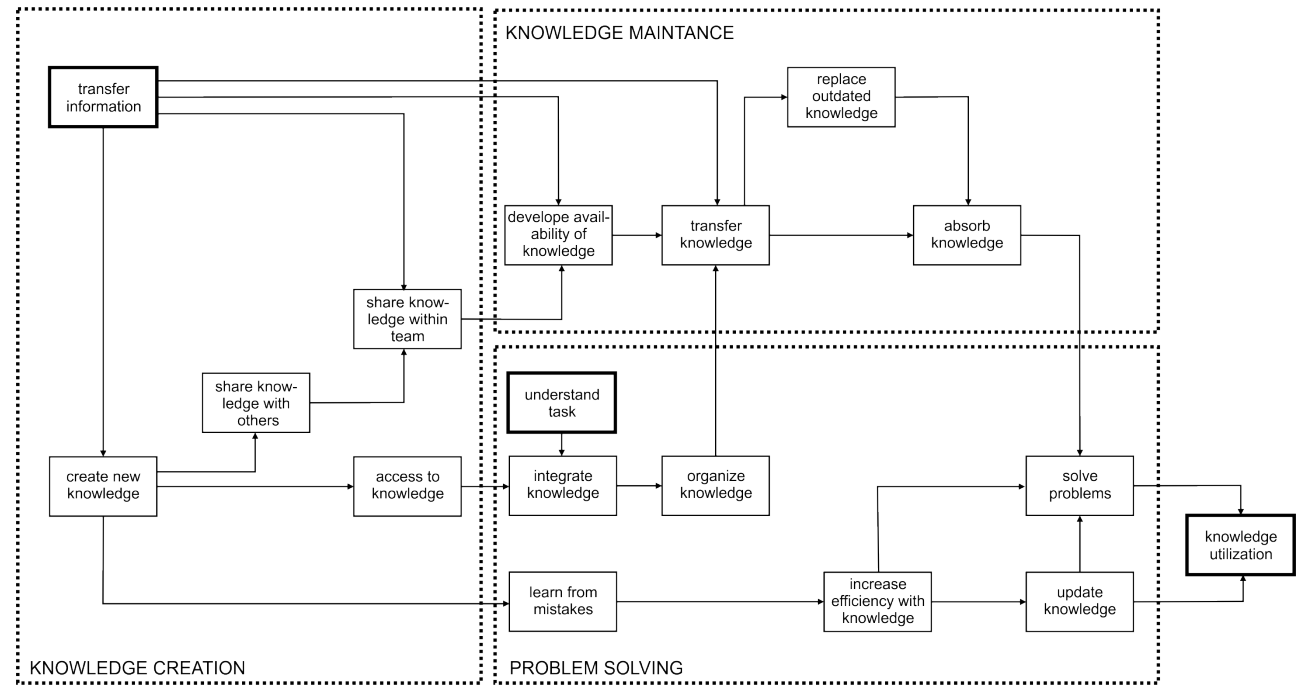

Figure 1. Casual path model of knowledge utilization in teamwork.

All paths are statistically significant as it is shown in discussion. The model consists of three main process of measured variables: knowledge creation, maintenance and problem solving. Each process has variables which have been measured before and after the experiments on a 5-point Likert scale. In the path model linear regressions were performed by enter method, standardized betas were calculated to ensure direct comparison.

\subsection{Experiment design and procedure}

The research took place at Budapest Business School, Faculty of Finance and Accountancy with part-time master students of the Finance and the Accounting Programmes between 2012 and 2014 (one experiment per year). A demographic survey was carried out among participants prior to the experiment to detect their attitudes and habits regarding teamwork and wiki usage. The frequency of using wiki platforms (social sites, cloud computing devices, and on-line collaboration tools) was measured for each participant and dichotomous variables were defined as a means of classifying them as wiki users or not. Teamwork habits were also measured with questions about how often and how many times participants work in teams. Dichotomous variables were also defined to classify whether they are team players or not. With this information teams of four people were formed with special regard to their demographic features (general attitude to IT and Web 2.0 tools) - as detailed in table 1.

According to these two dimensions 385 participants were divided into 97 teams with four members (3 groups had only 3 members) and it was ensured - according to demographic 
variables - that at least two of them were unfamiliar with each other or any other member of the team. In table 2 the distribution and number of teams in each category (and number of participants) is shown according to the year of experiment. The numbers in table 1 are the number of teams, and number is brackets are the number of team members.

Following this, the pre-experiment surveys were implemented, testing the attitudes towards collaboration of the teams for several attributes (general aspects of task/technology fit, decision quality, and productivity in teamwork).

Before experiments all teams were divided randomly into two (each segment defined by the two dimensions of familiarity with wiki tools and teamwork in table 1): 48 experimental teams with 190 (49.4\%) participants (including 2 deficient groups) and 49 control teams with 195 (50.6\%) participants (including 1 deficient group).

Table 1: Construction of the participant teams (team matrix)

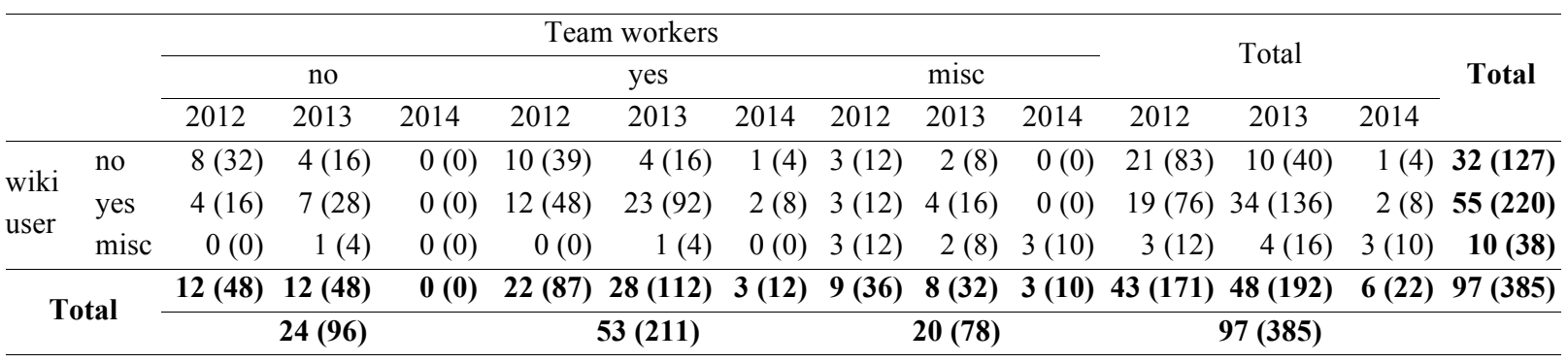

For the experimental teams a 60-minute training course on "Modern Web 2.0 based applications for on-line teamwork and mass collaboration" was held and some specific freeware applications (Skype, Dropbox, Google Drive, etc.) were demonstrated as Wang et al. (2013) suggest in their study. The intention was to promote commitment to solving their team tasks with these tools on-line without face-to-face communication. Control groups had no information about the research; those teams just received one of the experiment case studies to solve. The first sampling issue in the research was a pre-experiment survey about team members' attitude to teamwork. We measured many performance factors (see: Heidrich, Kasa, Shu, \& Chandler, 2015), however in this paper we focus only on knowledge utilization.

All the experiment's participants had to solve case studies with preference and intellectual tasks. After the experiments were finished and all the groups have completed their tasks a post-experiment survey was conducted with the same variables as the pre-experiment test. In this sense pre- and post-experiment results can be compared, such as control and experiment group results, or more specifically preference and intellectual tasks, or wiki and face-to-face groups also. 


\section{Discussion}

\subsection{Pre- and post-experiment results}

The significances in path model did not changed much after the experiment, however some remarkable changes in standardized betas have been occurred. In knowledge creation process, after the experiments knowledge share within the team and the development of knowledge availability is much more supported by information transfer. That means that after the experiment participants thought that after information is transformed into the team, it is much easier to share it, and make it available. After organizing knowledge, it became easier to transfer it in the team, however replacing outdated knowledge did not support better the absorption of knowledge. But this absorption contributed better problem solving. Learning from mistakes much more supported the efficiency of teamwork with knowledge and lead to knowledge update which forced better knowledge utilization in teamwork. These positive changes through the experiment have paired with some weakening in three relationships: share of knowledge outside the team did not supported better sharing within the team; access to knowledge did not grant better integration of knowledge; replace outdated knowledge did not support better absorption of knowledge. These changes can be seen in details in table 2 below, with all regression betas, their significance level, the determinant coefficients $(R)$ and its significance level. All sub-models are significant.

Table 2. Path model weights in pre vs. post experiment and control vs. experiment groups.

\begin{tabular}{|c|c|c|c|c|c|c|c|c|c|c|c|c|c|c|c|c|c|c|}
\hline \multicolumn{2}{|r|}{ Submodel } & \multicolumn{4}{|c|}{ PRE experiment } & \multicolumn{4}{|c|}{ POST experiment } & \multirow{2}{*}{$\Delta \beta$} & \multicolumn{4}{|c|}{ Controll group (F2F) } & \multicolumn{3}{|c|}{ Experiment group (WIKI) } & \multirow{2}{*}{$\Delta \beta$} \\
\hline Dependent & Independent & $\beta$ & $p$ & $R^{2}$ & $p$ & $\beta$ & $p$ & $\boldsymbol{R}^{2}$ & $p$ & & $\beta$ & $p$ & $R^{2}$ & $p$ & $\beta$ & $p$ & $R^{2} \quad p$ & \\
\hline \multirow{2}{*}{ knowledge utilization } & update knowledge & 0,212 & $* * *$ & \multirow{2}{*}{\multicolumn{2}{|c|}{$0,657 * * *$}} & 0,308 & $* * *$ & \multirow{2}{*}{0,753} & \multirow{2}{*}{$* * *$} & 0,10 & 0,285 & $5 * * *$ & \multirow{2}{*}{0,806} & \multirow{2}{*}{$6 * *$} & 0,337 & $* * *$ & \multirow{2}{*}{$0,698 * * *$} & 0,05 \\
\hline & solve problems & 0,658 & $* * *$ & & & 0,598 & $* * *$ & & & $-0,06$ & 0,651 & $* * *$ & & & 0,536 & *** & & $-0,12$ \\
\hline \multirow{3}{*}{ solve problems } & absorb knowledge & 0,433 & $* * *$ & \multirow{3}{*}{0,470} & \multirow{3}{*}{$* * *$} & 0,614 & $* * *$ & \multirow{3}{*}{0,712} & \multirow{3}{*}{$* * *$} & 0,18 & 0,623 & $3 * *$ & \multirow{3}{*}{0,697} & \multirow{3}{*}{$7 * *$} & 0,605 & $* * *$ & \multirow{3}{*}{$0,732 * * *$} & $-0,02$ \\
\hline & $\begin{array}{l}\text { increase efficiency with generated } \\
\text { knowledge }\end{array}$ & 0,247 & $* * *$ & & & 0,191 & $* * *$ & & & $-0,06$ & 0,171 & $* * *$ & & & 0,208 & $3 * *$ & & 0,04 \\
\hline & update knowledge & 0,105 & * & & & 0,165 & $* * *$ & & & 0,06 & 0,167 & $7 *$ & & & 0,164 & ** & & 0,00 \\
\hline update knowledge & $\begin{array}{l}\text { increase efficiency with generated } \\
\text { knowledge }\end{array}$ & 0,635 & $* * *$ & 0,403 & $* * *$ & 0,774 & $* * *$ & 0,598 & $* * *$ & 0,14 & 0,8 & $3 * * *$ & 0,641 & *** & 0,739 & $* * *$ & $0,547^{* * *}$ & $-0,06$ \\
\hline $\begin{array}{l}\text { increase efficiency with } \\
\text { generated knowledge }\end{array}$ & learn from mistakes & 0,363 & $* * *$ & 0,132 & $* * *$ & 0,499 & $* * *$ & 0,249 & $* * *$ & 0,14 & 0,671 & $* * *$ & 0,451 & $* * *$ & 0,586 & $5^{* * *}$ & $0,343 * * *$ & $-0,09$ \\
\hline learn from mistakes & create new knowledge & 0,435 & $* * *$ & 0,190 & $* * *$ & 0,432 & $* * *$ & 0,187 & $* * *$ & 0,00 & 0,463 & $3 * *$ & 0,214 & $4 * * *$ & 0,411 & $* * *$ & $0,169 * * *$ & $-0,05$ \\
\hline create new knowledge & transfer information & 0,563 & $* * *$ & 0,317 & $* * *$ & 0,485 & $* * *$ & 0,235 & $* * *$ & $-0,08$ & 0,495 & $5 * *$ & 0,245 & $5 * * *$ & 0,474 & *** & $0,224 * * *$ & $-0,02$ \\
\hline $\begin{array}{l}\text { share knowledge with other } \\
\text { participants }\end{array}$ & create new knowledge & 0,629 & $* * *$ & 0,396 & $* * *$ & 0,648 & $* * *$ & 0,420 & $* * *$ & 0,02 & 0,626 & $6 * * *$ & 0,392 & $2 * * *$ & 0,668 & $* * *$ & $0,446 * * *$ & 0,04 \\
\hline \multirow{2}{*}{ absorb knowledge } & replace outdated knowledge & 0,556 & $* * *$ & \multirow{2}{*}{0,474} & \multirow{2}{*}{$4 * * *$} & 0,408 & $* * *$ & \multirow{2}{*}{0,332} & $* * *$ & $-0,15$ & 0,357 & $7 * * *$ & 0245 & & 0,455 & $* * *$ & $0435 * * *$ & 0,10 \\
\hline & transfer knowledge & 0,218 & $* * *$ & & & 0,250 & $* * *$ & & 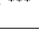 & 0,03 & 0,208 & $3 * *$ & 0,245 & & 0,300 & $* * *$ & 0,435 ; & 0,09 \\
\hline & transfer information & 0,218 & $* * *$ & & & 0,212 & $* * *$ & & & $-0,01$ & 0,285 & $5 * * *$ & & & 0,095 & & & $\mathrm{n} / \mathrm{a}$ \\
\hline transfer knowledge & develope availability of knowledge & 0,339 & $* * *$ & 0,411 & $* * *$ & 0,067 & & 0,484 & $* * *$ & $\mathrm{n} / \mathrm{a}$ & $-0,019$ & & 0,460 & $* * *$ & 0,197 & ** & $0,531 * * *$ & $\mathrm{n} / \mathrm{a}$ \\
\hline & organize knowledge & 0,201 & $* * *$ & & & 0,520 & $* * *$ & & & 0,32 & 0,531 & $* * *$ & & & 0,516 & $* * *$ & & $-0,02$ \\
\hline organize knowledge & integrate knowledge & 0,757 & $* * *$ & 0,573 & $* * *$ & 0,754 & $* * *$ & 0,568 & $* * *$ & 0,00 & 0,727 & $7 * * *$ & 0,529 & $\theta^{* * *}$ & 0,781 & $* * *$ & $0,611^{* * *}$ & 0,05 \\
\hline intearate knowled & understand details of the task & 0,154 & $* * *$ & 0466 & $* * *$ & 0,236 & $* * *$ & 0325 & $* *$ & 0,08 & 0,213 & $3 *$ & 0380 & $* * *$ & 0,262 & *** & $0382 * * *$ & 0,05 \\
\hline integrale knowledge & access to new knowledge & 0,612 & $* * *$ & 0,466 & Pan & 0,456 & $* * *$ & 0,385 & ${ }^{*}$ & $-0,16$ & 0,482 & $2^{* * *}$ & 0,389 & 96.4 & 0,428 & *** & $0,382 \cdots$ & $-0,05$ \\
\hline access to new knowledge & create new knowledge & 0,583 & $* * *$ & 0,340 & $* * *$ & 0,637 & $* * *$ & 0,406 & $* * *$ & 0,05 & 0,653 & $3 * *$ & 0,427 & $7 * *$ & 0,621 & $* * *$ & $0,385^{* * *}$ & $-0,03$ \\
\hline share knowledge with team & share knowledge with other participants & 0,719 & $* * *$ & 0711 & & 0,296 & $* * *$ & 0468 & & $-0,42$ & 0,344 & $4^{* * *}$ & 0430 & & 0,253 & $* * *$ & $0517 * * 2>$ & $-0,09$ \\
\hline members & transfer information & 0,188 & $* * *$ & 0,711 & Fit & 0,488 & $* * *$ & 0,468 & s & 0,30 & 0,407 & $7 * *$ & 0,439 & 9 ats & 0,576 & *** & 0,517 * * & 0,17 \\
\hline replace outdated knowledge & transfer knowledge & 0,483 & $* * *$ & 0,233 & $* * *$ & 0,503 & $* * *$ & 0,253 & $* * *$ & 0,02 & 0,500 & $* * *$ & 0,250 & $* * *$ & 0,506 & *** & $0,257 * * *$ & 0,01 \\
\hline develope availability of & transfer information & 0,229 & $* * *$ & 0.352 & & 0,421 & $* * *$ & 0,492 & & 0,19 & 0,527 & $7 * *$ & 0.518 & $* * *$ & 0,262 & $2 * *$ & $0.484 *$ & $-0,27$ \\
\hline & share knowledge with team members & 0,426 & $* * *$ & & & 0,354 & $* * *$ & 0,492 & & $-0,07$ & 0,269 & $* * *$ & & & 0,490 & $* * *$ & & 0,22 \\
\hline${ }^{*} p<.05, * * p<.01, * * *$ & & $\imath=385$ & & & & $n=385$ & & & & & $n=192$ & & & & $n=193$ & & & \\
\hline
\end{tabular}


In order to highlight the difference between actual control and experiment groups' results we calculated $\Delta \beta$.

Control (face-to-face technologies) and experimental (wiki technologies) group statistics were also compared and too great differences were not experienced. Knowledge share was much more supported by information transfer in experimental groups, and it led to better development of knowledge availability. However, control groups over performed knowledge utilization by problem solving (they had stronger causal relationship) and they can build the availability of knowledge through information transfer better. In every other relationship the differences between standardized betas are not significant.

\subsection{Control and experiment group results for intellectual and preference tasks}

For intellectual tasks experiment groups had much better results after the experiment than the control groups. Almost every relationship has become stronger in knowledge creation and maintenance processes as it is shown in table 3 .

Table 3. Path model weights for intellectual and preference tasks.

\begin{tabular}{|c|c|c|c|c|c|c|c|c|c|c|c|c|c|c|}
\hline \multicolumn{2}{|r|}{ Submodel } & \multicolumn{2}{|c|}{ Intellectual task ${ }^{*} \mathrm{~F} 2 \mathrm{~F}$} & \multicolumn{2}{|c|}{ Intellectual task * WIKI } & \multirow{2}{*}{$\Delta \beta$} & \multicolumn{4}{|c|}{ Preference task * F2F } & \multicolumn{3}{|c|}{ Preference task * WIKI } & \multirow{2}{*}{$\Delta \beta$} \\
\hline Dependent & Independent & $\beta \quad p$ & $R^{2}$ & $\beta$ & $\boldsymbol{R}^{2}$ & & $\beta$ & $p$ & $\boldsymbol{R}^{2}$ & $p$ & $\beta$ & $p$ & $R^{2} \quad p$ & \\
\hline \multirow{2}{*}{ knowledge utilization } & update knowledge & 0,029 & \multirow{2}{*}{$0,902 * * *$} & 0,154 & \multirow{2}{*}{$0,284 *$} & $\mathrm{n} / \mathrm{a}$ & 0,071 & & \multirow{2}{*}{\multicolumn{2}{|c|}{$0,803 * * *$}} & 0,256 & & \multirow{2}{*}{$0,894 * * *$} & $\mathrm{n} / \mathrm{a}$ \\
\hline & solve problems & $0,929 * * *$ & & 0,421 & & $\mathrm{n} / \mathrm{a}$ & 0,834 & $* * *$ & & & 0,716 * & *** & & $-0,12$ \\
\hline \multirow{3}{*}{ solve problems } & absorb knowledge & $0,469 *$ & \multirow{3}{*}{$0,647 * *$} & 0,007 & \multirow{3}{*}{0,733} & $\mathrm{n} / \mathrm{a}$ & 0,576 & $* *$ & \multirow{3}{*}{\multicolumn{2}{|c|}{$0,794 * * *$}} & 0,815 * & *** & \multirow{3}{*}{$0,744 * * *$} & 0,24 \\
\hline & $\begin{array}{l}\text { increase efficiency with generated } \\
\text { knowledge }\end{array}$ & $0,318 *$ & & $0,386^{*}$ & & 0,07 & 0,076 & & & & 0,075 & & & $\mathrm{n} / \mathrm{a}$ \\
\hline & update knowledge & 0,183 & & $0,574 *$ & & $\mathrm{n} / \mathrm{a}$ & 0,323 & & & & 0,048 & & & $\mathrm{n} / \mathrm{a}$ \\
\hline update knowledge & $\begin{array}{l}\text { increase efficiency with generated } \\
\text { knowledge }\end{array}$ & $0,828 * * *$ & $0,686^{* * *}$ & $0,774 * * *$ & $0,599 * * *$ & $-0,05$ & 0,785 & $* * *$ & 0,617 & $* * *$ & $0,821 *$ & $* * *$ & $0,674 * * *$ & 0,04 \\
\hline $\begin{array}{l}\text { increase efficiency with } \\
\text { generated knowledge }\end{array}$ & learn from mistakes & $0,549 * *$ & $0,301 * *$ & $0,758 * * *$ & $0,574 * * *$ & 0,21 & 0,723 & $* * *$ & 0,522 & $* * *$ & 0,321 & & 0,103 & n/a \\
\hline learn from mistakes & create new knowledge & $0,371 *$ & $0,138 *$ & $0,686 * * *$ & $0,471 * * *$ & 0,32 & 0,442 & $*$ & 0,195 & * & 0,506 * & * & $0,256 *$ & 0,06 \\
\hline create new knowledge & transfer information & 0,323 & 0,104 & $0,59 * *$ & $0,348 * *$ & $\mathrm{n} / \mathrm{a}$ & 0,585 , & $* *$ & 0,342 & ** & 0,62 * & ** & $0,384 * *$ & 0,04 \\
\hline $\begin{array}{l}\text { share knowledge with other } \\
\text { participants }\end{array}$ & create new knowledge & $0,42 *$ & $0,176 *$ & $0,741^{* * *}$ & $0,550 * * *$ & 0,32 & 0,605 * & $* *$ & $0,366^{*}$ & ** & $0,43 *$ & $*$ & $0,185 *$ & $-0,18$ \\
\hline \multirow{2}{*}{ absorb knowledge } & replace outdated knowledge & 0,034 & \multirow{2}{*}{0,145} & $0,63 * *$ & \multirow{2}{*}{$0,480^{* *}$} & $\mathrm{n} / \mathrm{a}$ & 0,015 & & \multirow{2}{*}{\multicolumn{2}{|c|}{$0,255 * *$}} & 0,308 & & \multirow{2}{*}{0,159} & $\mathrm{n} / \mathrm{a}$ \\
\hline & transfer knowledge & 0,367 & & 0,091 & & $\mathrm{n} / \mathrm{a}$ & 0,498 & & & & 0,119 & & & $\mathrm{n} / \mathrm{a}$ \\
\hline \multirow{3}{*}{ transfer knowledge } & transfer information & 0,227 & \multirow{3}{*}{$0,539 * * *$} & 0,167 & \multirow{3}{*}{0,491} & $\mathrm{n} / \mathrm{a}$ & 0,411 & * & \multirow{3}{*}{\multicolumn{2}{|c|}{$0,553 * *$}} & 0,021 & & \multirow{3}{*}{$0,549 * *$} & $\mathrm{n} / \mathrm{a}$ \\
\hline & develope availability of knowledge & $0,320 *$ & & $0,513 *$ & & 0,19 & 0,094 & & & & 0,347 & & & $\mathrm{n} / \mathrm{a}$ \\
\hline & organize knowledge & $0,494 * *$ & & 0,100 & & $\mathrm{n} / \mathrm{a}$ & 0,347 & & & & 0,449 * & $*$ & & 0,10 \\
\hline organize knowledge & integrate knowledge & $0,609 * * *$ & $0,371 * * *$ & $0,797 * * *$ & $0,635 * * *$ & 0,19 & 0,672 & $* * *$ & 0,451 & $* * *$ & 0,754 * & *** & $0,569 * * *$ & 0,08 \\
\hline \multirow{2}{*}{ integrate knowledge } & understand details of the task & 0,309 & $0,416 * *$ & 0,231 & $0,557 * * *$ & $\mathrm{n} / \mathrm{a}$ & 0,433 & & 0,446 & $* *$ & 0,274 & & $0,091 * * *$ & $\mathrm{n} / \mathrm{a}$ \\
\hline & access to new knowledge & $0,395^{*}$ & & $0,544^{*}$ & & 0,15 & 0,398 & $*$ & & & 0,047 & & & $\mathrm{n} / \mathrm{a}$ \\
\hline access to new knowledge & create new knowledge & $0,504 * *$ & $0,254^{* *}$ & $0,621^{* *}$ & $0,385^{* *}$ & 0,12 & 0,873 & $* * *$ & 0,763 & $* * *$ & 0,413 * & $*$ & $0,170 *$ & $-0,46$ \\
\hline share knowledge with team & share knowledge with other participants & $0,494 * *$ & $0.447 * * *$ & $0,321 *$ & $0.744 * * *$ & $-0,17$ & 0,548 & * & $0419:>$ & & 0,521 & ** & $0602 * * *$ & $-0,03$ \\
\hline members & transfer information & $0,422 * *$ & & $0,615 * *$ & & 0,19 & 0,174 & & & & 0,384 * & * & & $\mathrm{n} / \mathrm{a}$ \\
\hline replace outdated knowledge & transfer knowledge & $0,353 *$ & $0,124 *$ & $0,650^{* *}$ & $0,423 * *$ & 0,30 & 0,497 & $*$ & 0,247 & $*$ & 0,692 * & $* * *$ & $0,479 * * *$ & 0,20 \\
\hline develope availability of & transfer information & $0,496 *$ & $0281 *$ & $-0,332$ & $0356 *$ & $\mathrm{n} / \mathrm{a}$ & 0,546 & $* *$ & $0683=$ & & 0,437 * & $*$ & $0572 *$ & $-0,11$ \\
\hline knowledge & share knowledge with team members & 0,067 & 0,281 & $0,842 *$ & 0,350 & $\mathrm{n} / \mathrm{a}$ & 0,429 & & 0,083 & & 0,403 * & * & $0,3 / 2$ & $-0,03$ \\
\hline
\end{tabular}

For preference type tasks this improvement cannot be significantly separated between experimental and control groups. However, some relationships were also over performed by wiki users: knowledge organization - knowledge transfer - outdated knowledge 
replacement and knowledge absorption - problem solving. Nevertheless, better problemsolving does not support better knowledge utilization for preference tasks.

\section{References}

Bean, L. A., \& Hott, D. D. (2005). Wiki: A speedy new tool to manage projects. Journal of Corporate Accounting \& Finance, 16(5), 3-8.

Berndt, T. J. (1992). Child Development. New York: Holt, Rinehart and Winston.

Hadjerrouit, S. (2014). Wiki as a collaborative writing tool in teacher education: Evaluation and suggestions for effective use. Computers in Human Behavior, 32, 301-312.

Heidrich, B., Kasa, R., Shu, W., \& Chandler, N. (2015). Worlds Apart But Not Alone- How Wiki-Technologies Influence Productivity and Decision-making in Student Groups. Decision Sciences Journal of Innovative Education, 13(2), 221-246.

Li, M. (2013). Individual novices and collective experts: Collective scaffolding in wikibased small group writing. System, 41(3), 752-769.

Lin, C., Chuang, Y.-H., \& Shu, W. (2012). The Effectiveness of Wikis' Knowledge Sharing on Decision Quality, Productivity, and Satisfaction. In J. G. Cegarra (Ed.), Proc. of the 13th European Conf. on Knowledge Mngt. (p. 209). Cartagena, Spain: Universidad Politécnica de Cartagena.

Mattison, D. (2003). Quickiwiki, swiki, twiki, zwiki, and the plone wars: Wiki as PIM and collaborative content tool. Searcher: The Mag. for Database Prof., 11(4), 32-48.

McAfee, A. P. (2006). Enterprise 2.0: The Dawn of Emergent Collaboration. MIT Sloan Management Review, 47(3), 21.

Shu, W., \& Chuang, Y.-H. (2011). The Behavior of Wiki Users. Social Behavior and Personality (SSCI), 39(6), 851-864.

Shu, W., \& Chuang, Y.-H. (2012). Wikis as an effective group writing tool: A study in taiwan. Online Information Review, 36(1), 89.

Shu, W., \& Lee, S. (2003). Beyond Productivity - Productivity and the Three Types of Efficiency of Information Technology Industry. Information and Software Technology, 45(8), $513-24$.

Trkman, M., \& Trkman, P. (2009). A wiki as intranet: A critical analysis using the delone and McLean model. Online Information Review, 33(6), 1087-1102.

Wang, J., Zou, B., Wang, D., \& Xing, M. (2013). Students' perception of a wiki platform and the impact of wiki engagement on intercultural communication. System, 41(2), 245-256.

Zhang, Y., Fang, Y., Wei, K.-K., \& He, W. (2013). Cognitive elaboration during wiki use in project teams: An empirical study. Decision Support Systems, 55(3), 792-801.

Zigurs, I., \& Buckland, B. K. (1998). A theory of task/technology fit and group support systems effectiveness. MIS Quarterly, 22(3), 313-334. 